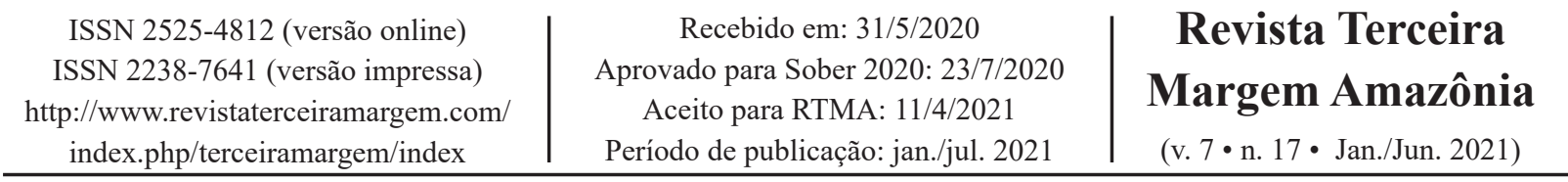

Como citar o artigo:

MALANSKI, P. D.; CHAVES, P. T. T.; SOUZA, J. P. de S.; SCHIAVI, S. M. de A. Impactos da covid-19 sobre o trabalho na agricultura e em cadeias produtivas na perspectiva da grande mídia. Revista Terceira Margem Amazônia, v. 7, n. 17, p. 171-189, 2021. DOI: http://dx.doi.org/10.36882/2525-4812.2021v7i17.p171-189

\title{
IMPACTOS DA COVID-19 SOBRE O TRABALHO NA AGRICULTURA E EM CADEIAS PRODUTIVAS NA PERSPECTIVA DA GRANDE MÍDIA
}

\author{
Priscila Duarte Malanski ${ }^{1}$ \\ Priscilla Tiara Torrezan Chaves ${ }^{2}$ \\ José Paulo de Souza ${ }^{3}$ \\ Sandra Mara de Alencar Schiavi ${ }^{4}$
}

\begin{abstract}
Resumo: A agricultura vem passando pela crise provocada pela pandemia da covid-19. Medidas necessárias para evitar a circulação do vírus têm afetado o mundo, em razão da paralisação de atividades produtivas e de serviços. A agricultura e suas cadeias produtivas são classificadas como serviços essenciais, para que não haja ruptura no suprimento de alimentos. Isso implica que trabalhadores rurais, da agroindústria e da distribuição devem manter suas atividades, se adaptar ao contexto sanitário crítico e responder às demandas do mercado. Os efeitos desse cenário sobre o trabalho ainda não são claros, tendo em vista a situação inédita e de rápidas mudanças e medidas. Informações veiculadas pela grande mídia oferecem conteúdo que reflete o cenário atual sobre os efeitos da pandemia. O objetivo deste estudo é identificar os impactos da pandemia por covid-19 no trabalho em agricultura e cadeias produtivas, a partir da perspectiva da grande mídia nacional e internacional. A análise textual lexicométrica foi realizada em 28 notícias veiculadas pela grande mídia entre março e maio de 2020. Cinco principais impactos da covid-19 no trabalho foram identificados: saúde do trabalhador, disponibilidade de mão de obra, tempo de trabalho, ruptura da cadeia e mercado de trabalho. Tais impactos são estruturados em três níveis: propriedade agrícola, cadeia agrícola e economia e sociedade. As implicações econômicas e sociais desses impactos na agricultura e nas cadeias produtivas foram discutidas.
\end{abstract}

Palavras-chave: covid-19, trabalho, agricultura, cadeias produtivas, crise.

\footnotetext{
1 Engenheira-agrônoma, doutora em Ciência Animal, Programa de Pós-Graduação em Administração - Universidade Estadual de Maringá, Maringá, PR.

E-mail: priscilamalanski2@gmail.com

(D) https://orcid.org/0000-0002-4145-3431

2 Administradora, Maringá, PR.

E-mail: priscilla.1007@hotmail.com

(iD) https://orcid.org/0000-0001-6776-6543

3 Administrador, doutor em Engenharia de Produção, professor da Universidade Estadual de Maringá, Maringá, PR. E-mail: jpsouza@uem.br (iD https://orcid.org/0000-0002-5659-1044

4 Economista, doutora em Engenharia de Produção, pró-reitora da Pró-Reitoria de Planejamento e Desenvolvimento Institucional da Universidade Estadual de Maringá, Maringá, SP.

E-mail: smaschiavi@uem.br

(iD https://orcid.org/0000-0002-3285-1243
} 


\title{
IMPACTS OF COVID-19 ON WORK IN AGRICULTURE AND SUPLLY CHAINS FROM MEDIA VIEW
}

\begin{abstract}
Agriculture is pressured by the crisis caused by the covid-19 pandemic. Necessary actions to prevent the circulation of viruses are affecting the whole world due to the interruption of productive and services activities. Agriculture and its supply chains are classified as essential services in order to avoid disruption of food supply. This implies that agricultural, agribusiness and distribution workers must maintain their activities, adapt to the critical health context and respond to market demands. The effects of this scenario on work are not yet clear. Considering the unprecedented situation of systemic rapid changes and actions, information conveyed by the large media can show the current scenario on the effects of the pandemic. The aim of this study was to identify the impacts of the covid-19 pandemic on work in agriculture and in the supply chains from the perspective of the major national (Brazil) and international media. A textual lexicometric analysis was performed on 28 news published in Portuguese, English, and French by the mainstream media between March and May 2020. Five main impacts of covid-19 on work were identified: worker health, availability of labor, working time, supply chain interruption, and labor market. Such impacts are structured at three levels: farm, agricultural chain, economy and society. The economic and social implications of these impacts on agriculture and production chains were discussed.
\end{abstract}

Keywords: covid-19, work, agriculture, supply chains, crisis.

\section{Introdução}

A agricultura é responsável por $28 \%$ do total de empregos, o que a torna um dos setores que mais empregam no mundo (WORLD BANK, 2019). No Brasil, mais de 15 milhões de pessoas trabalham na agricultura (IBGE, 2017). Esses números representam a importância que ela tem para a economia do Brasil e do mundo por meio da geração de emprego e renda.

No entanto, o setor vem passando por crises e incertezas ligadas à covid-19, pandemia de ordem sanitária, cujo meio de prevenção ao contágio é o distanciamento social. Medidas necessárias para evitar a circulação do vírus têm afetado o mundo em razão da interrupção de atividades produtivas e de serviços. Neste sentido, o poder público de vários países decretou a paralisação de serviços classificados como não essenciais.

Essa medida afetou cerca de $80 \%$ dos trabalhadores no mundo, acarretando decrescimento nas horas trabalhadas, perda salarial e até desemprego (INTERNATIONAL LABOUR ORGANIZATION, 2020). Esses impactos têm sido ainda mais severos para trabalhadores informais, que não contam com proteção social nesse período de crise (FAO, 2020a).

A agricultura e suas cadeias produtivas são classificadas como serviços essenciais, visto que as atividades de produção, processamento e distribuição de alimentos devem ser contínuas para que não haja ruptura no suprimento de alimentos. Contudo, estudos apontam que a agricultura e suas cadeias produtivas enfrentam diversas dificuldades para que isso não aconteça. A primeira é a redução na demanda de alimentos ligada à paralisação de serviços não essenciais (fechamento de restaurantes, escolas e refeitórios) (LARUE, 2020). A segunda dificuldade é a adaptação da alta demanda de produtos específicos (e.g.: cereais e ovos) ligada à estocagem de produtos e à mudança dos hábitos alimentares das famílias durante a quarentena (LARUE, 2020; MASUNAGA, 2020; RICHARDS; RICKARD, 2020). A terceira dificuldade são os embargos ligados às fronteiras fechadas, onde mercadorias e pessoas não podem circular como antes da 
pandemia (LARUE, 2020; MCEWAN et al., 2020; RICHARDS; RICKARD, 2020). A quarta dificuldade é a adaptação dos locais de trabalho e organização das equipes para que possam trabalhar em local sanitariamente seguro e respeitando as recomendações dos órgãos de saúde (MCEWAN et al., 2020; RICHARDS; RICKARD, 2020). Isso implica que trabalhadores rurais, da agroindústria e da distribuição devem manter suas atividades, buscando adaptar-se ao contexto sanitário crítico e responder às demandas do mercado.

Apesar da rápida síntese de pesquisadores sobre as dificuldades do setor, os efeitos da pandemia sobre o trabalho ainda não são claros, sobretudo diante de uma situação inédita em que boa parte da população mundial está sob lockdown, em que orientações sanitárias e medidas restritivas são tomadas rapidamente. A ausência de resultados de estudos estruturados, por sua vez, limita a extrapolação de experiência e a indicação de caminhos seguros e previsíveis. Neste sentido, informações veiculadas pela grande mídia oferecem um vasto campo de exploração, cujo conteúdo reflete o quadro atual sobre os impactos da pandemia que estão ocorrendo, seja no âmbito nacional, seja no âmbito internacional. Indicam, além disso, experiências empíricas e descrição das ocorrências e de protocolos de ação associados à pandemia, com efeito sobre o trabalho.

Diante desse contexto, o objetivo deste estudo é identificar os impactos da pandemia da covid-19 no trabalho em agricultura e cadeias produtivas, a partir da perspectiva da grande mídia nacional e internacional. Na próxima sessão são detalhados os procedimentos metodológicos, incluindo o contexto de realização desta pesquisa. Em seguida, os impactos da covid-19 no trabalho, nos panoramas nacional e internacional, são descritos. As implicações econômicas e sociais desses impactos na agricultura e cadeias produtivas são discutidos.

\section{Procedimentos metodológicos}

\section{Contexto da pesquisa}

Os impactos da pandemia da covid-19 na agricultura são o foco de estudos do Projeto de Extensão Covid-19 e Impactos no Agronegócio e Cadeias Produtivas. Trata-se de uma iniciativa de professores, pesquisadores e alunos de pós-graduação (mestrado, doutorado e pós-doutorado) da Universidade Estadual de Maringá (UEM), ligados ao Grupo de Estudos em Estruturas Coordenadas (Gecor) e ao Programa de Pós-Graduação em Administração (PPA/UEM).

O trabalho é apenas um dos seis temas que o grupo investiga a partir de publicações científicas e não científicas (e.g.: relatórios de organizações internacionais como a OIT e FAO, boletins técnicos, notícias da mídia para o grande público). O objetivo do grupo é sintetizar e produzir informações e conhecimento para as comunidades científica e não científica (e.g.: gestores públicos, agricultores e instituições representantes da categoria), a fim de oferecer subsídios para entender esse momento de crise e repensar as estratégias para enfrentá-la (SOUZA; SCHIAVI, 2020). 


\section{Coleta e análise dos dados}

Este estudo se inspira em análises similares sobre as informações veiculadas pela grande mídia e questões sanitárias e de saúde pública, como a dengue (VILLELA; NATAL, 2014) e o câncer (CASTRO, 2009).

Assim, quatro etapas foram realizadas para identificar os principais impactos da pandemia da covid-19 no trabalho, em particular na agricultura e em cadeias produtivas, segundo a grande mídia. A primeira etapa foi a coleta de dados que representassem a opinião pública. Textos de notícias publicados na mídia digital para o grande público (jornais, blogs e revistas) foram coletados a partir de: 1) busca via motor de pesquisa na internet utilizando as palavras-chave "covid-19", "agricultura", "trabalho"; 2) notícias recebidas via Digimind, uma plataforma de monitoramento de mídias virtuais. A fim de obter panorama nacional e internacional, textos em português, inglês e francês foram selecionados. Ao total, 28 notícias publicadas entre fim de março e início de maio de 2020 na mídia digital foram identificadas e são apresentadas na Tabela 1. Ressaltamos que o interesse deste trabalho é o de mapear e sintetizar os primeiros impactos da pandemia na agricultura, isso implica na não representatividade estatística dos dados levantados. Além disso, tendo em vista a evolução da crise, podem surgir outros impactos não identificados por este estudo.

Tabela 1. Notícias consultadas.

\begin{tabular}{|c|c|c|c|}
\hline Língua & Título da notícia & Fonte & Data de publicação \\
\hline \multirow{8}{*}{ Português } & $\begin{array}{l}\text { ABPA lança vídeo sobre intensificação de cuidados } \\
\text { contra a Covid-19 }\end{array}$ & $\begin{array}{l}\text { Notícias Agrícolas } \\
\text { Associação Brasileira } \\
\text { de Proteína Animal }\end{array}$ & $3 / 4 / 2020$ \\
\hline & $\begin{array}{l}\text { Cafeicultores estão com medo de faltar mão de obra } \\
\text { para a colheita que começa em breve }\end{array}$ & Guimarães, E. & $3 / 4 / 2020$ \\
\hline & $\begin{array}{l}\text { Emater/RS-Ascar orienta transportadores de } \\
\text { alimentos em tempos de coronavírus }\end{array}$ & $\begin{array}{l}\text { Centro de Inteligência } \\
\text { Orgânicos }\end{array}$ & $3 / 4 / 2020$ \\
\hline & $\begin{array}{l}\text { Colheita de café é iniciada em RO e Seagri orienta } \\
\text { sobre cuidados e prevenção ao coronavírus }\end{array}$ & G1 RO & $11 / 4 / 2020$ \\
\hline & $\begin{array}{l}\text { Covid-19 não deve prejudicar desempenho do PIB } \\
\text { do agro, diz Cepea }\end{array}$ & Canal Rural & $14 / 4 / 2020$ \\
\hline & $\begin{array}{l}\text { Cafeicultor adapta processo de colheita aos tempos } \\
\text { de pandemia }\end{array}$ & Globo Rural & $22 / 4 / 2020$ \\
\hline & Como a Covid-19 mudou o dia a dia dos agricultores & Globo Rural & $3 / 5 / 2020$ \\
\hline & $\begin{array}{l}\text { Colheita do café no Sul de MG começa com boas } \\
\text { expectativas, mesmo diante de pandemia }\end{array}$ & G1 Globo & $4 / 5 / 2020$ \\
\hline \multirow{7}{*}{ Inglês } & $\begin{array}{l}\text { COVID-19 measures could cause 'devastating' } \\
\text { labour shortage in EU farming }\end{array}$ & Euractiv & $25 / 3 / 2020$ \\
\hline & $\begin{array}{l}\text { Opinion: Farmers may not be infected but are } \\
\text { certainly affected }\end{array}$ & Livemint & $31 / 3 / 2020$ \\
\hline & Farmers Prioritize Worker Health and Safety & Farm Bureau & $1 \% / 4 / 2020$ \\
\hline & Farm Methodically for Safety & Teagasc & $1 \% / 4 / 2020$ \\
\hline & Regional Farm Labour Database being set up & Teagasc & $2 / 4 / 2020$ \\
\hline & $\begin{array}{l}\text { Checklist for Reducing Workforce Impact from } \\
\text { COVID-19 }\end{array}$ & Safe Food Queensland & $3 / 4 / 2020$ \\
\hline & $\begin{array}{l}\text { US agriculture: Can it handle coronavirus, labor } \\
\text { shortages and panic buying? }\end{array}$ & USA Today & $4 / 4 / 2020$ \\
\hline
\end{tabular}


Tabela 1. Continuação.

\begin{tabular}{|c|c|c|c|}
\hline Língua & Título da notícia & Fonte & Data de publicação \\
\hline \multirow{6}{*}{ Inglês } & $\begin{array}{l}\text { ILO: COVID-19 causes devastating losses in } \\
\text { working hours and employment }\end{array}$ & $\begin{array}{l}\text { International Labour } \\
\text { Organization }\end{array}$ & $7 / 4 / 2020$ \\
\hline & $\begin{array}{l}\text { COVID-19: impact could cause equivalent of } 195 \\
\text { million job losses, says ILO chief }\end{array}$ & UN News & $8 / 4 / 2020$ \\
\hline & $\begin{array}{l}\text { Farmworkers risk coronavirus infection to keep the } \\
\text { U.S. fed }\end{array}$ & Borunda, A. & $10 / 4 / 2020$ \\
\hline & German farms need nearly 300,000 seasonal workers & Euractiv & $11 / 4 / 2020$ \\
\hline & $\begin{array}{l}\text { COVID-19, Informal Workers and WIEGO's Work } \\
\text { during this Crisis }\end{array}$ & $\begin{array}{l}\text { Women in Informal } \\
\text { Employment: } \\
\text { Globalizing and } \\
\text { Organizing }\end{array}$ & $14 / 4 / 2020$ \\
\hline & $\begin{array}{l}\text { The Impact of COVID-19 on Child Labourin } \\
\text { Agriculture }\end{array}$ & ECLT Foundation & - \\
\hline \multirow{7}{*}{ Francês } & $\begin{array}{l}\text { Covid19 - Protéger sa santé et celle des intervenants } \\
\text { en élevage Les gestes à respecter pour les } \\
\text { interventions du vétérinaire }\end{array}$ & GDS & $2 / 4 / 2020$ \\
\hline & [Covid-19] Des leviers pour réorganiser le travail & $\begin{array}{l}\text { Idele (Institut de } \\
\text { l'Elevage) }\end{array}$ & $14 / 4 / 2020$ \\
\hline & [Covid-19] Gestion des salariés pendant la crise & $\begin{array}{l}\text { Idele (Institut de } \\
\text { l'Elevage) }\end{array}$ & $14 / 4 / 2020$ \\
\hline & $\begin{array}{l}\text { [Covid-19] Préserver la santé des personnes } \\
\text { intervenant sur l'élevage }\end{array}$ & $\begin{array}{l}\text { Idele (Institut de } \\
\text { l'Elevage) }\end{array}$ & $14 / 4 / 2020$ \\
\hline & $\begin{array}{l}\text { Covid-19 \& Sécurité alimentaire: L'Inde face à la } \\
\text { crise de l'emploi }\end{array}$ & Cirad & $15 / 4 / 2020$ \\
\hline & $\begin{array}{l}\text { [Covid-19] Témoignages d'éleveurs Bovins Lait de } \\
\text { l'est }\end{array}$ & $\begin{array}{l}\text { Idele (Institut de } \\
\text { l'Elevage) }\end{array}$ & $21 / 4 / 2020$ \\
\hline & $\begin{array}{l}\text { [Covid-19] Témoignages d'éleveurs Bovins viande } \\
\text { du Limousin }\end{array}$ & $\begin{array}{l}\text { Idele (Institut de } \\
\text { l'Elevage) }\end{array}$ & $21 / 4 / 2020$ \\
\hline
\end{tabular}

Fonte: Elaborado pelos autores.

A segunda etapa foi a preparação dos dados para análise das notícias. Um corpus foi constituído para cada uma das três línguas de notícias publicadas com o objetivo de: 1) preservar o rigor da análise textual na língua original da publicação; 2) comparar o cenário brasileiro ao cenário internacional.

A terceira etapa foi a análise dos três corpus. A análise por meio de nuvem de palavras foi realizada com o software de análise textual Atlas.Ti. A nuvem de palavras é uma técnica de análise textual lexicométrica baseada na frequência de termos dentro de um corpus, na qual a alta repetição de palavras permite a extração de palavras-chave essenciais do corpus (SHAHID et al., 2017). Foram excluídos da nuvem preposições, pronomes e artigos definidos e indefinidos. O resultado é mostrado em forma de grupo de palavras que representam as palavras mais frequentes do corpus. Quanto maior o tamanho da palavra, maior a sua frequência.

A quarta etapa foi a análise comparativa entre as três nuvens de palavras obtidas na etapa anterior. O objetivo foi identificar tópicos similares e diferentes entre o panorama nacional (nuvem de palavras em português) e o panorama internacional (nuvem de palavras em inglês e francês). 


\section{Resultados}

\section{Impactos da covid-19 no trabalho na agricultura e em cadeias de produção agrícolas no Brasil}

No Brasil, quatro impactos principais da covid-19 envolvendo o trabalho na agricultura e nas cadeias produtivas foram identificados (Figura 1).

Figura 1. Impactos da covid-19 no trabalho em agricultura: principais palavras em português.

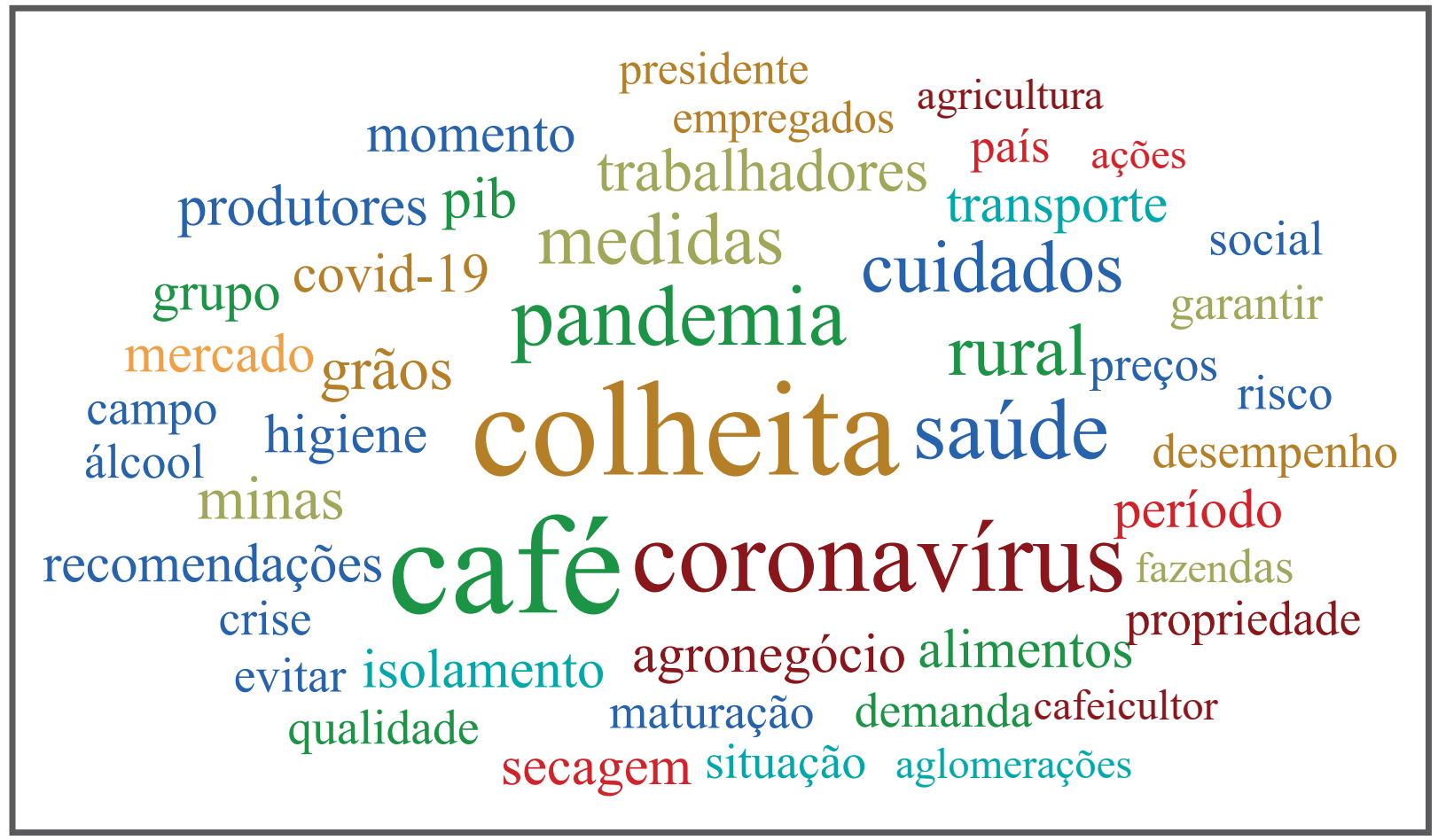

Fonte: Elaborado pelos autores.

O primeiro diz respeito à colheita do café (e.g.: colheita, café, maturação, secagem, cafeicultor, qualidade). $\mathrm{O}$ destaque nessa cadeia está ligado às práticas da colheita e pós-colheita que requerem muitos trabalhadores, o que pode causar aglomerações nos cafezais, nos transportes, como demonstra o trecho a seguir: “[...] os pés já estão prontos para a colheita, o que gera outra situação de risco para o contágio da doença. Isso porque é necessária muita mão de obra, o que causa aglomerações [...].” (GLOBO RURAL, 2020).

O segundo impacto é na saúde dos trabalhadores do campo (e.g.: saúde, coronavírus, cuidados, covid-19, pandemia, recomendações, evitar, álcool, higiene). Esse impacto é associado principalmente às orientações de prevenção da covid-19 adaptadas para o meio rural, visto que trabalhadores rurais precisam continuar trabalhando para garantir o abastecimento e a alimentação de todos, além de sua renda. Essa preocupação é ratificada no seguinte trecho: “A preservação da saúde do trabalhador e a garantia de oferta de alimentos à população são nossas prioridades. É uma questão de paz social" (ASSOCIAÇÃO BRASILEIRA DE PROTEÍNAANIMAL, 2020). 
O terceiro impacto se refere à disponibilidade e possibilidade de contratar mão de obra (e.g.: transporte, isolamento). A quarentena e as restrições à mobilidade interferem na locomoção dos trabalhadores para a zona rural em momentos da produção que requerem muita mão de obra, o que se ratifica pela afirmação: "A preocupação é que a quarentena do coronavírus se prolongue por mais tempo podendo interferir no deslocamento de mão de obra na colheita" (GUIMARÃES, 2020).

O quarto impacto refere-se a economia e mercado de trabalho (e.g.: PIB, desempenho, preço, mercado). Nesse caso, os principais impactos da pandemia da covid-19 sobre o PIB do agronegócio e o mercado de trabalho do setor são avaliados. A notícia revela:

Até o momento, pesquisadores do Cepea esperam um desempenho satisfatório no PIB do agronegócio, sobretudo da agropecuária - havendo, portanto, grande disparidade com a economia em geral, cujas projeções de desempenho pioram dia a dia. Em termos setoriais, as perspectivas de impacto da crise são ruins para muitas atividades agropecuárias e agroindustriais que são grandes geradoras de postos de trabalho [...] (CANAL RURAL, 2020).

Foram também identificadas medidas tomadas com o objetivo de mitigar esses impactos. Isso ocorre principalmente com relação às orientações de prevenção à covid-19 para os trabalhadores do campo. Algumas entidades brasileiras estão oferecendo manuais, notícias e vídeos para que tais informações sejam disponibilizadas aos agricultores, processadores e transportadores. Um desses materiais, destacados a seguir, é produzido pela Emater-RS:

[...] um documento que orienta os transportadores de alimentos que abastecem o Estado, para que adotem medidas que evitem a multiplicação do coronavírus. [...] O foco das recomendações [...] é para a importância da higiene pessoal e para o manuseio de objetos e equipamentos durante o transporte e a entrega de frutas, verduras ou leguminosas em mercados ou mesmo em domicílios (CENTRO DE INTELIGÊNCIA EM ORGÂNICOS, 2020).

Além disso, instituições de apoio $\left(\right.$ Emater $^{5}$ e $\left.\mathrm{ABPA}^{6}\right)$, proprietários rurais e gestores estão buscando maneiras de adaptar a colheita e a pós-colheita em tempos de covid-19. Um exemplo é apresentado na seguinte afirmação: "Com a pandemia de coronavírus foi preciso adaptar as rotinas das fazendas para garantir uma colheita com segurança, conforme indica os órgãos de saúde. (...) A colheita deve seguir normalmente, desde que os proprietários estejam atentos às normas" (MENDES, 2020).

\section{Impactos da covid-19 no trabalho na agricultura e em cadeias de produção agrícolas no mundo}

Ao se considerar o contexto mundial, na nuvem de palavras em língua inglesa, três principais impactos da covid-19 no trabalho em cadeias produtivas foram identificados (Figura 2).

\footnotetext{
Empresa de Assistência Técnica e Extensão Rural.

6 Associação Brasileira de Proteína Animal.
} 
Figura 2. Impactos da covid-19 no trabalho em cadeias produtivas: principais palavras em inglês.

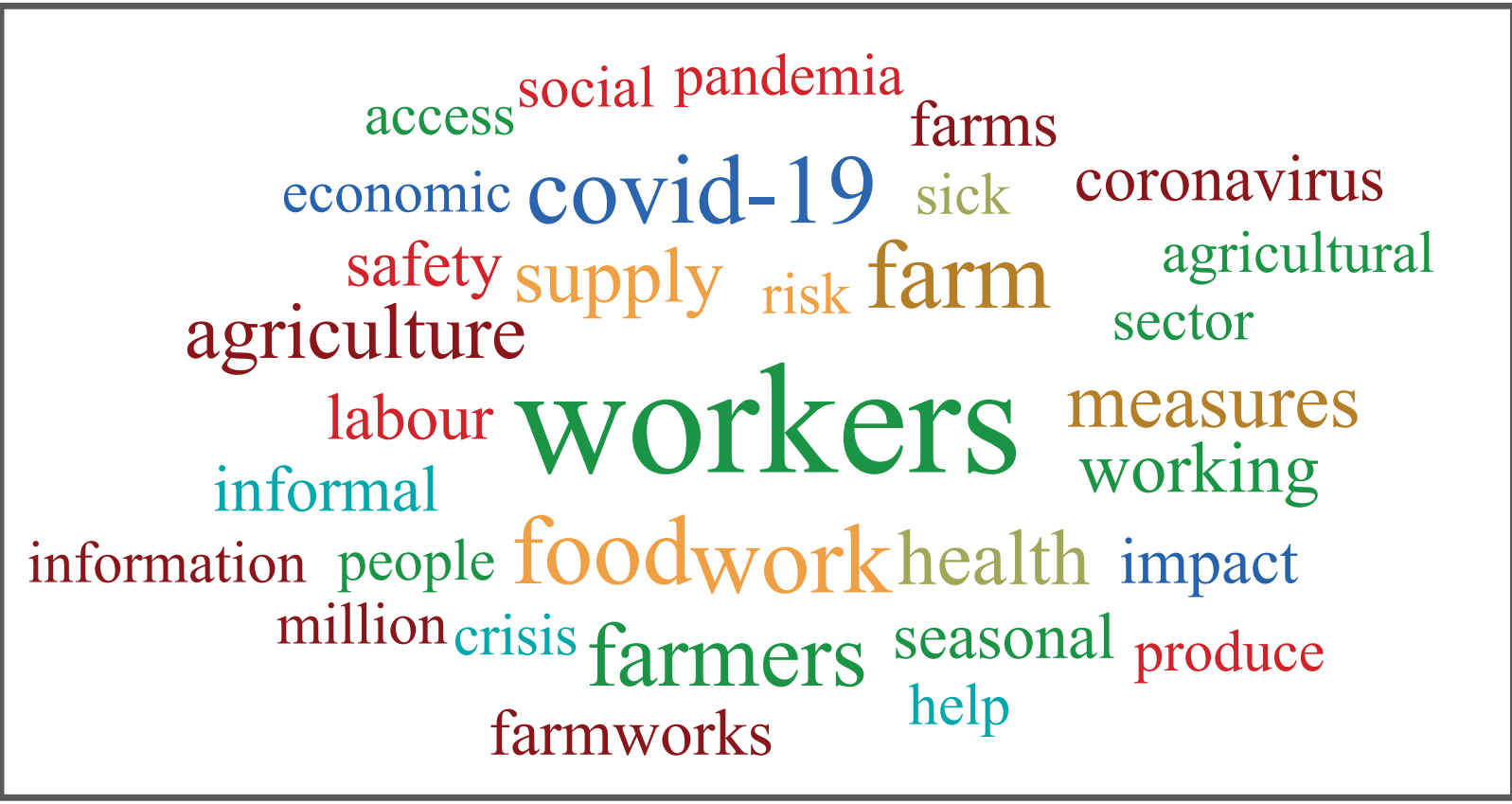

Fonte: Elaborado pelos autores.

O primeiro refere-se ao impacto na saúde dos trabalhadores (e.g.: health, sick), que está ligado às orientações de prevenção para evitar infecções pelo vírus durante o trabalho, principalmente para as categorias mais vulneráveis (e.g.: trabalhadores informais). O foco da mídia tem sido alertar e divulgar os cuidados necessários para a prevenção, conforme destacado em dois trechos:

"[...] o documento fornece uma lista de verificação das medidas de gerenciamento de risco de covid-19 para instalações de produção de alimentos, fazendas e galpões de embalagem" (SAFE FOOD QUEENSLAND, 2020, tradução nossa).

“A crise atual é uma crise de saúde pública e econômica que aumenta os riscos para os trabalhadores pobres e suas famílias, que não têm acesso adequado a planos de saúde nos melhores tempos" (WOMEN IN INFORMAL EMPLOYMENT: GLOBALIZING AND ORGANIZING, 2020, tradução nossa).

Nota-se ainda que esse impacto é mais relatado pela mídia, atingindo as categorias de trabalhadores em vulnerabilidade, como o trabalhador rural, informal e sazonal (e.g.: workers, informal, seasonal, farmworkers). Isso ocorre porque, para muitos deles, o acesso às informações e à proteção social é difícil, visto que muitos têm acesso limitado a saúde, água, saneamento e segurança, ratificado na seguinte afirmação:

“[...] os trabalhadores sazonais são particularmente vulneráveis à contração do vírus e, portanto, contribuem para a sua disseminação, uma vez que 'frequentemente vivem e trabalham em más condições, muitas vezes sem acesso a necessidades sanitárias e roupas de proteção" (EURACTIV, 2020, tradução nossa). 
O segundo impacto é sobre a cadeia de suprimentos (e.g.: food, supply, demand, labour, work, working), em que há uma preocupação com sua continuidade, pois os agricultores precisam continuar trabalhando para que não falte alimento e não seja interrompida a cadeia de suprimentos. Por outro lado, a cadeia de suprimentos ainda precisa se adaptar às mudanças na demanda. Essa adaptação está ligada ao rápido crescimento da demanda de alimentos causado pela incerteza da crise gerada pela pandemia, conforme destacado:

\begin{abstract}
No momento, não há relatos de trabalhadores rurais infectados. Mas toda a cadeia de suprimentos de produtos frescos pode estar em perigo se o vírus varrer as comunidades agrícolas rurais com tanta força quanto em outros lugares. [...] as interrupções relacionadas à COVID-19 - desde demanda sem precedentes por alguns produtos até mudanças na equipe de lojas e armazéns - aumentaram muitos dos sistemas que normalmente funcionam quase sem problemas. (BORUNDA, 2020, tradução nossa).
\end{abstract}

O terceiro diz respeito ao impacto econômico que a covid-19 já vem causando no trabalho (e.g:. economic, crisis, work, labour), conforme demostra o trecho a seguir:

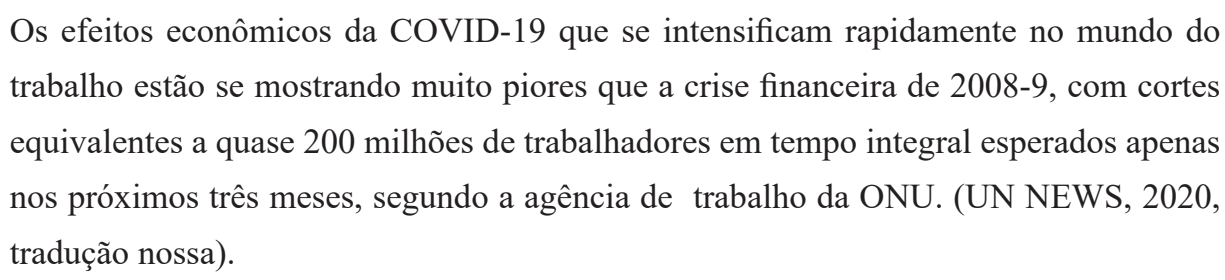

Ao se tratar da nuvem de palavras em língua francesa, quatro impactos no trabalho em cadeias produtivas foram identificados (Figura 3).

Figura 3. Impactos da covid-19 no trabalho em agricultura: principais palavras em francês.

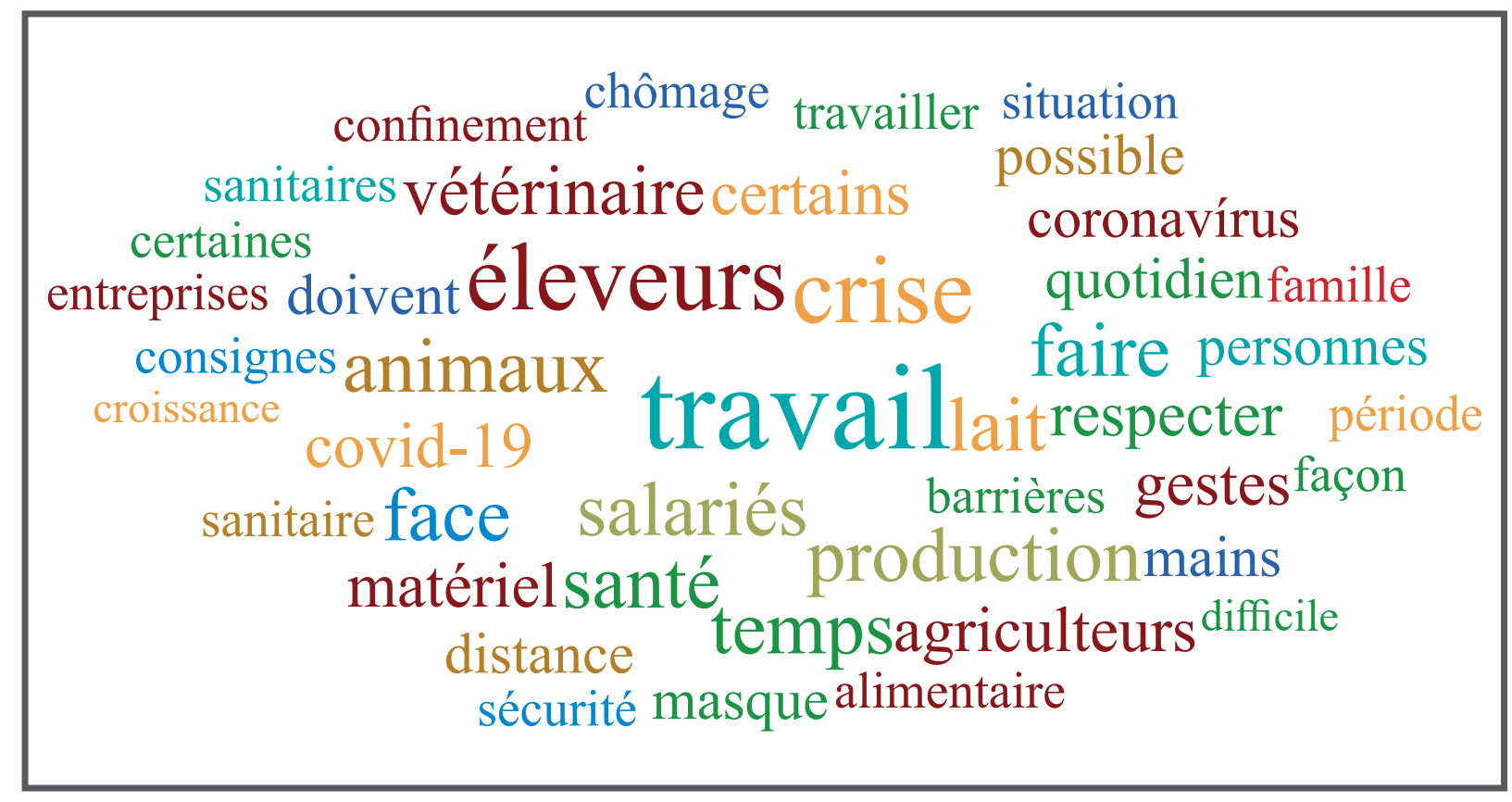

Fonte: Elaborado pelos autores. 
O primeiro impacto refere-se à saúde de agricultores e outros agentes da cadeia (e.g.: éleveurs, salariés, véterinaire). Esse impacto está ligado às mudanças necessárias para a prevenção da transmissão e infecção da covid-19 durante o trabalho quotidiano (e.g.: covid-19, coronavirus, travail, gestes, respecter, barières, consignes, mains, face, distance, securité, matériel, masque), seja ele realizado por trabalhadores familiares e assalariados em propriedades rurais (e.g.: éleveurs, salariés, agriculteurs, personnes, famille), seja por veterinários que prestam serviços nas propriedades (e.g.: véterinaires, animaux). Por outro lado, as tarefas quotidianas continuam as mesmas, de acordo com o período. Os trechos a seguir demonstram tal impacto:

As portas da leiteria (onde fica estocado o leite na propriedade) ficam abertas, assim o técnico tem menos contato com as coisas e nos cumprimentamos de longe. (...) são gestos de barreira para limitar a contaminação. Os pecuaristas dão atenção especial à limpeza da leiteria para preservar a própria saúde e a saúde do técnico. As fechaduras e o acesso são sistematicamente desinfetadas. O mesmo cuidado é tomado com o inseminador. Alguns pecuaristas propõem baldes com água e guardanapos para limpar as botas e as mãos. (IDELE, 2020a, tradução nossa).

Em geral, os veterinários vão até as propriedades para as intervenções urgentes, como os nascimentos de bezerros na primavera, grandes problemas sempre podem acontecer (partos difíceis...). Para os 'pequenos machucados', o diagnóstico é passado à distancia por telefone. (IDELE, 2020b, tradução nossa).

Por outro lado, as tarefas quotidianas continuam as mesmas de acordo com o período, conforme o destacado:

Na metade de março os pecuaristas estavam bem ocupados com a preparação da saída dos animais dos estábulos para a pastagem, o que constitui sempre um pico de trabalho que se adiciona às tarefas habituais, como a alimentação, as observações e cuidados com os animais. Entre a verificação e reparação das cercas antes da liberação dos animais nos piquetes, a organização dos lotes entre os piquetes e a saída progressiva dos diferentes lotes de animais são atividades obrigatórias neste período do ano. A ensilagem começou, com o início da primavera quente e seca, o acúmulo de temperatura foi alcançado rapidamente e a colheita da forragem de qualidade está a pleno vapor. Igualmente, a semeadura de primavera começou (IDELE, 2020b, tradução nossa).

O segundo impacto é na disponibilidade da mão de obra assalariada que trabalha nas propriedades. Duas razões para a indisponibilidade são indicadas: 1) por questões de saúde do trabalhador, que é afastado do trabalho com atestado médico; 2) em consequência do lockdown, como é o caso dos pais que não podem ir trabalhar porque precisam cuidar dos filhos incapacitados de irem à escola ou creche, conforme destacado: "Alguns assalariados não puderam trabalhar porque tinham que cuidar das crianças ou estavam doentes." (IDELE, 2020a, tradução nossa).

O terceiro impacto diz respeito ao tempo de trabalho dos agricultores nas propriedades (e.g.: temps, travail). Esse impacto está ligado à adaptação do trabalho em função das orientações de prevenção acompanhadas de mudanças na condução técnica de animais e culturas que podem reduzir o tempo de trabalho, conforme o trecho seguinte: 
As simplificações da condução técnica são, muitas vezes, fáceis de se colocar em prática e são reversíveis. Elas precisam de pouco investimento financeiro e levam a diminuir as performances do rebanho e, assim, reduzir o ritmo de produção. Isso permite liberar um tempo para si, para sua família e, também, para realizar as medidas sanitárias contra o coronavírus." (IDELE, 2020c, tradução nossa).

O quarto impacto é no mercado de trabalho. A redução ou a paralisação das atividades tem acarretado em desemprego (e.g.: chômage). Esse desemprego pode ser integral ou parcial, como demonstram os trechos a seguir:

"No caso de decréscimo de atividades ligadas a esta crise, o governo (francês) disponibiliza um sistema de desemprego parcial que assegura uma parte dos custos com o empregado." ((IDELE, 2020d, tradução nossa).

No dia 24 de março de 2020, Nerendra Modi, Primeiro Ministro da União Indiana, anuncia confinamento de três semanas [...]. De um dia pro outro, estes 'trabalhadores migrantes' ficam sem salário [...]. Mais de 80\% dos empregos na Índia estão na economia informal, sem contrato de trabalho, sem proteção social, aposentadoria ou outros benefícios. (CIRAD, 2020, tradução nossa).

\section{Similaridades e diferenças entre os impactos da covid-19 no Brasil e no mundo}

Três impactos da covid-19 sobre o trabalho na agricultura e nas cadeias de produção ocorrem tanto em nível nacional quanto internacional: 1) impacto na saúde dos trabalhadores e agentes da cadeia, cujo foco são as orientações de prevenção contra a doença durante o trabalho; 2) impacto na disponibilidade de mão de obra, principalmente em função de medidas de proteção à saúde (e.g.: lockdown, quarentena, isolamento social); 3) impacto econômico com foco principalmente no corte de trabalhadores, ou seja, no mercado de trabalho. Os dois primeiros impactos afetam a execução de trabalhos agrícolas que demandam muita mão de obra em um momento peculiar da produção. Especificamente para o caso do Brasil, identificou-se que a covid-19 gerou barreiras que dificultam a colheita do café.

Em nível internacional, outros impactos foram identificados. De um lado, impactos na cadeia de produção: 1) mudanças no tempo de trabalho nas propriedades; 2) ruptura da cadeia, desde a produção (redução da produção de alimentos) à distribuição de alimentos.

Finalmente, os impactos da covid-19 sobre o trabalho na agricultura e nas cadeias de produção, da perspectiva da grande mídia, são estruturados em três níveis interligados pelos impactos: 1) propriedade agrícola: caracterizado pelos impactos que mudam a rotina de trabalho (e.g.: saúde do trabalhador, disponibilidade de mão de obra, tempo de trabalho); 2) cadeia agrícola: caracterizado pela ruptura da cadeia desde a produção até a distribuição, que, por sua vez, é consequência dos impactos na propriedade agrícola; 3) economia e sociedade: caracterizado pelos impactos no mercado de trabalho (e.g.: desemprego), que, por sua vez, é consequência da ruptura da cadeia. Essas relações são sintetizadas na Figura 4, em que os impactos na propriedade agrícola associados à covid-19 abrangem as relações sociais e afetam a economia. 
Figura 3. Síntese dos impactos da covid-19 sobre o trabalho na agricultura e nas cadeias produtivas.

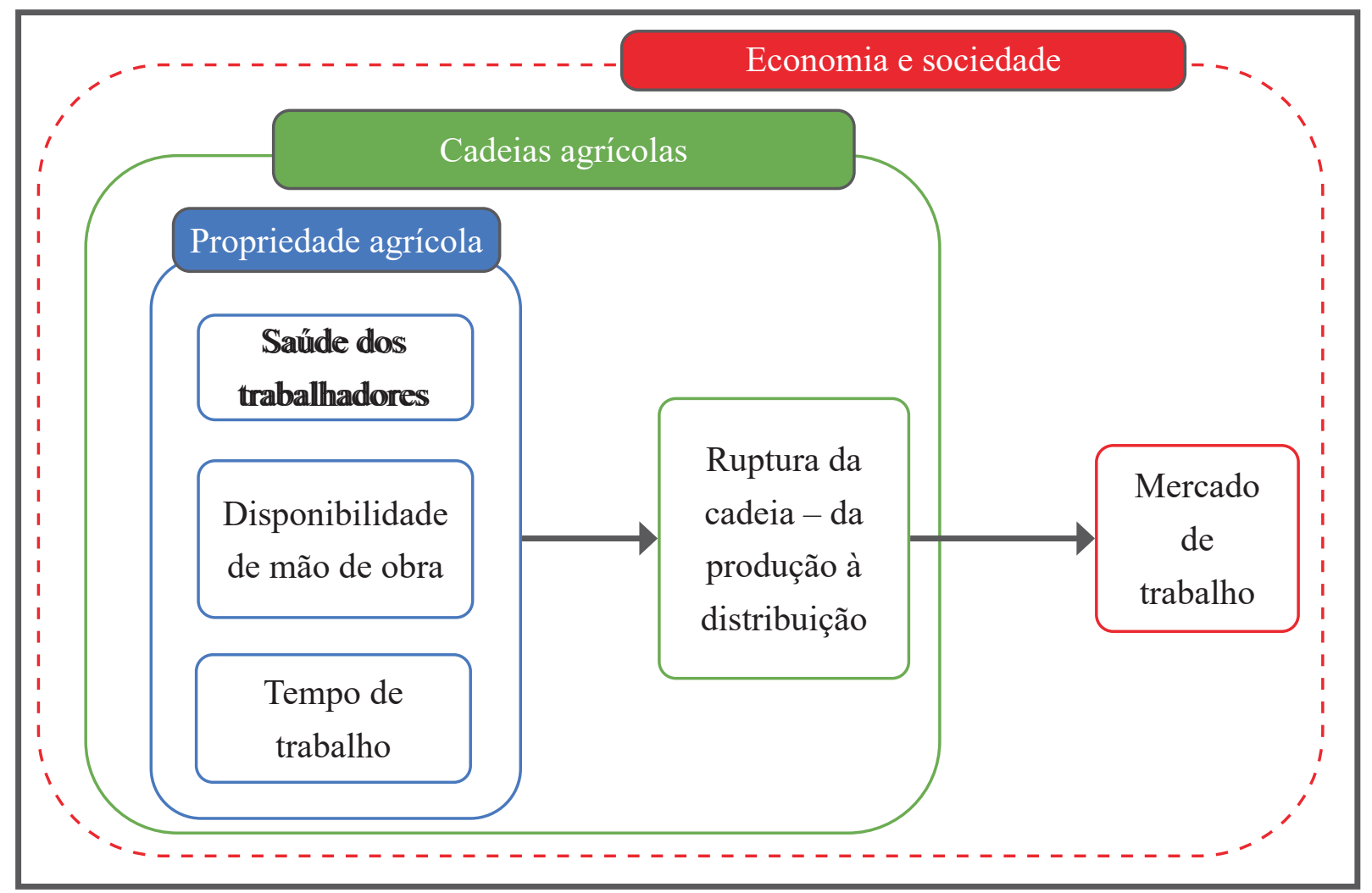

Fonte: Elaborado pelos autores.

\section{Discussão}

Cinco principais impactos da covid-19 no trabalho na agricultura e em cadeias produtivas agrícolas foram identificados, segundo a grande mídia: saúde do trabalhador, disponibilidade de mão de obra, tempo de trabalho, ruptura da cadeia e mercado de trabalho.

De um lado, nossos resultados mostraram os impactos que confirmam as previsões de dificuldades enfrentadas pelo setor agrícola e suas cadeias de produção (LARUE, 2020; MCEWAN et al., 2020; RICHARDS; RICKARD, 2020), como: 1) a seguridade sanitária de locais de trabalho de acordo com recomendações de órgãos de saúde a fim de prevenir a transmissão da doença durante o trabalho; 2) a falta de mão de obra, em virtude de medidas de proteção sanitárias que restringem a mobilidade de pessoas, e a ruptura da cadeia da produção à distribuição. Por outro lado, nossos resultados mostraram novos impactos que não foram previstos, a exemplo do tempo de trabalho nas propriedades agrícolas.

Outro resultado original foi a identificação das conexões entre os diferentes impactos, tendo em vista que estudos anteriores trataram de potenciais impactos da covid-19 focados em cadeias específicas, como cadeias de frutas e vegetais (RICHARDS; RICKARD, 2020) e a cadeia suína (MCEWAN et al., 2020). Nossos resultados mostram que as conexões entre os diferentes impactos são estruturadas em três níveis: propriedade agrícola, cadeia agrícola e economia e socieda- 
de. A relação de causalidade entre os impactos de cada nível começa com as sinergias entre os diferentes impactos na rotina de trabalho na propriedade agrícola, que, por sua vez, tem impacto direto nas cadeias produtivas, e finalmente atingem a economia e a sociedade.

Os impactos identificados neste estudo não são completamente novos para pesquisadores especializados no tema trabalho na agricultura (MALANSKI et al., 2019). A falta de mão de obra e as dinâmicas do mercado de trabalho rural são problemas amplamente discutidos na literatura internacional. Contudo, a pandemia reforça tais problemas. Por exemplo, a crise da falta de mão de obra agrícola pode se agravar em países que praticam agricultura intensiva e utilizam amplamente a força de trabalho de imigrantes para sanar essa falta, como é o caso do setor de frutas e legumes nos Estados Unidos, Canadá e Inglaterra (MARTIN et al., 2016; PREIBISCH, 2010; ROGALY, 2008). De forma similar, no Brasil, a falta de mão de obra sazonal pode se agravar, tendo em vista que grandes massas de trabalhadores rurais migram sazonalmente para responder à alta demanda por mão de obra, como é o caso da cana-de-açúcar (MENEZES et al., 2012). O setor sucroalcoleiro ainda contrata trabalhadores migrantes, embora a mecanização da colheita tenha reduzido 68\% das contratações nos últimos anos (COVER; MENEZES, 2020). Neste sentido, nossos resultados mostraram que no Brasil o foco está na falta de trabalhadores rurais para a colheita do café. Isso está ligado ao fato de o Brasil ser o maior produtor e exportador de café do mundo (USDA, 2021) e o início da pandemia estar próximo da época de colheita do fruto, período em que a planta conclui o enchimento dos grãos, ganhando mais densidade, e entra no processo de maturação (GUIMARÃES, 2020). Nesse caso, não se pode deixar por muito tempo o fruto maduro no pé, pois isso acarreta em perda de qualidade e produtividade (G1 RO, 2020). É necessário colher no tempo correto e para isso é preciso de muita mão de obra, o que pode causar aglomerações no campo e nos transportes. Apesar do crescente uso de colheitadeiras, a colheita manual do café ainda é uma prática comum, principalmente em propriedades cujo relevo não permite a mecanização, ou em pequenas propriedades (ALVES; LINDNER, 2020; CROCCO et al., 2017).

No Brasil e no mundo, percebe-se que instituições privadas e públicas procuram encontrar medidas para reduzir os impactos da covid-19 no trabalho. No caso das medidas de mobilidade que geram escassez de mão de obra, a França solicitou aos estudantes disponíveis, trabalhadores autônomos e trabalhadores a meio-tempo (part-time) que se mobilizem no setor agrícola (EURACTIV, 2020a). A União Europeia também propôs que as fronteiras se abram para os trabalhadores agrícolas, com cooperação entre os países. No entanto, o foco são os trabalhadores locais, incentivando-os, inclusive, com oferta de salários mais altos (EURACTIV, 2020a).

Outro problema agravado pela pandemia é a situação de trabalhadores rurais vulneráveis, como informais, migrantes e pobres. As vulnerabilidades desses trabalhadores são diversas. As condições de emprego e de trabalho para informais e migrantes já eram consideradas críticas antes mesmo da covid-19 (BARRIENTOS; KRITZINGER, 2004; MINKOFF-ZERN; SLOAT, 2017). A pandemia os expõe ainda mais à vulnerabilidade socioeconômica em razão do difícil acesso ou do não acesso a benefícios e proteção social ligados ao trabalho, e da queda na renda de famílias devido a restrições de movimento de mão de obra e mercadorias (FAO, 2020a). Sabendo-se que $80 \%$ dos trabalhadores rurais no mundo são informais, a situação é alarmante, e políticas públicas de seguridade e proteção social devem ser aplicadas e ampliadas (FAO, 2020b). 
Esse quadro socioeconômico reforça a vulnerabilidade à pobreza das famílias rurais. Cerca de 770 milhões de pessoas no mundo vivem na extrema pobreza, e 75\% delas vivem em zonas rurais (FAO, 2017). Ainda, a pobreza aumenta a vulnerabilidade estrutural da população rural, caracterizada pelo baixo investimento em saneamento básico e pela infraestrutura precária dos serviços de saúde (FAO, 2020b). Dessa forma, além da ameaça à saúde pública, a covid-19 está causando perturbações econômicas e sociais que ameaçam os meios de produção, reprodução e o bem-estar de milhões de agricultores e trabalhadores rurais, principalmente os mais vulneráveis, como informais e migrantes.

Finalmente, nossos resultados mostraram que o trabalho na agricultura e em cadeias produtivas está por trás da maioria dos impactos da covid-19 no setor. Contudo, os primeiros relatórios de organismos internacionais ou publicações científicas focaram principalmente nas consequências desses impactos (economia, mercado de trabalho, abastecimento de alimentos) (DEATON; DEATON, 2020; FREITAS et al., 2020; IVANOV, 2020; MCKIBBIN; FERNANDO, 2020; PORSSE et al., 2020).

Cabe ao poder público e à iniciativa privada definir medidas de suporte e de proteção visando a estabelecer um ambiente seguro para que a produção de alimentos e a segurança dos trabalhadores caminhem juntos. Assim, a gravidade dos impactos da covid-19 vai depender da duração da pandemia, das restrições mais severas à mobilidade e da efetividade das ações do poder público, seja de apoio aos empregados (garantir a renda e gerar demanda) ou às empresas (manter empregos e garantir a oferta). Portanto, o agravamento da crise da covid-19 no Brasil e no mundo, bem como políticas públicas ineficazes, podem comprometer o desempenho econômico e produtivo do agronegócio, assim como deteriorar ainda mais a situação do mercado de trabalho em função do aumento do desemprego, que por fim aumenta a vulnerabilidade socioeconômica da população.

Este trabalho foi realizado com publicações veiculadas pela grande mídia entre final de março e início de maio de 2020. Levando em conta o curto período sob investigação, um dos limites desta pesquisa é a especificidade temporal dos impactos identificados. Tendo em vista a evolução da crise causada pela pandemia, outros impactos não identificados por este estudo podem surgir. Assim, sugere-se o monitoramento das informações veiculadas pela grande mídia ao longo da crise para mapear e sintetizar o quadro evolutivo dos impactos da covid-19 sobre o trabalho na agricultura e em cadeias produtivas, seja no âmbito nacional ou internacional.

\section{Considerações Finais}

Cinco principais impactos da covid-19 no trabalho foram identificados: saúde do trabalhador, disponibilidade de mão de obra, tempo de trabalho, ruptura da cadeia e mercado de trabalho. Tais impactos são estruturados em três níveis: propriedade agrícola, cadeia agrícola e economia e sociedade.

No Brasil, ao se considerar o contexto das colheitas de produtos agrícolas, as implicações da saúde do trabalhador e sua disponibilidade para executar as atividades são destacadas nos estudos. Além disso, o mercado de trabalho, com possível redução de postos, aparece como preocupação resultante da pandemia, assim como seu impacto sobre a renda e o consumo. De forma 
positiva, diferentes iniciativas públicas e privadas vêm apresentando orientações que buscam mitigar impactos e oferecer sustentação para as atividades do setor agrícola.

Em termos de saúde do trabalhador e orientações de prevenção à doença, focou-se nas categorias mais vulneráveis, notadamente os trabalhadores informais e sazonais, com baixos níveis de proteção social. A preocupação com a sustentabilidade da cadeia de suprimentos, que depende do trabalho e se adapta às mudanças no consumo, direciona muitos estudos. Nesse caso, a disponibilidade de mão de obra, impactada pelos afastamentos por questões de saúde e do lockdown, afetam o desempenho das cadeias, reduzindo produtividade, na consideração das mudanças nas rotinas operacionais e redução de horas de trabalho.

Conclui-se que as mudanças causadas pela covid-19 nas propriedades rurais, associadas ao trabalho e à disponibilidade de mão de obra, refletem diretamente na cadeia produtiva e no sistema de suprimentos, a exemplo da disponibilidade de alimentos, afetando diversos setores econômicos, com impactos sociais significativos. A preocupação com a saúde e proteção do trabalhador, em nível nacional e mundial, apontada nos estudos, oferece aos gestores subsídios e orientações de prevenção e mitigação. As decisões, quando apoiadas nas evidências encontradas, possibilitam melhores condições para enfretamento e sucesso das ações frente à pandemia e favorecem a sociedade nesse enfrentamento.

\section{Agradecimento}

Este trabalho recebeu apoio da Coordenação de Aperfeiçoamento de Pessoal de Nível Superior (Capes).

\section{Referências}

ALVES, F. D.; LINDNER, M. Agronegócio do café no sul de Minas Gerais: territorialização, mundialização e contradições. Revista OKARA: Geografia em debate, v. 14, n. 2, p. 433-451, 2020.

ASSOCIAÇÃO BRASILEIRA DE PROTEÍNA ANIMAL. ABPA lança vídeo sobre intensificação de cuidados contra a Covid-19. Notícias Agrícolas, 3 abr. 2020. Disponível em: https://www.noticiasagricolas. com.br/noticias/politica-economia/256194-abpa-lanca-video-sobre-intensificacao-de-cuidados-contra-a-covid-19.html\#.YLFEVrdKiUk. Acesso em: 9 abr. 2020.

BARRIENTOS, S.; KRITZINGER, A. Squaring the circle: global production and the informalization of work in South African fruit exports. Journal of International Development, v. 16, n. 1, p. 81-92, 2004.

BORUNDA, A. Farmworkers risk coronavirus infection to keep the U.S. fed. National Geographic, 10 Apr. 2020. Disponível em: https://www.nationalgeographic.com/science/2020/04/farmworkers-risk-coronavirus-infection-keep-us-fed/. Acesso em: 28 abr. 2020.

CANAL RURAL. Covid-19 não deve prejudicar desempenho do PIB do agro, diz Cepea. Disponível em: https://www.canalrural.com.br/economia/covid-19-nao-deve-prejudicar-desempenho-do-pib-do-agro-diz-cepea/. Acesso em: 28 abr. 2020.

CASTRO, R. Câncer na mídia: uma questão de saúde pública. Revista Brasileira de Cancerologia, v. 55, n. 1, p. 41-48, 2009. 
CENTRO DE INTELIGÊNCIA EM ORGÂNICOS. Emater/RS-Ascar orienta transportadores de alimentos em tempos de coronavírus. Rio, 3 abr. 2020. Disponível em: https://ciorganicos.com.br/noticia/emater-rs-ascar-orienta-transportadores-de-alimentos-em-tempos-de-coronavirus/. Acesso em: 9 abr. 2020 .

CIRAD. Covid-19 \& Sécurité alimentaire | L'Inde face à la crise de l'emploi. Disponível em: https:// www.cirad.fr/actualites/toutes-les-actualites/articles/2020/science/covid-19-securite-alimentaire-1-inde-face-a-la-crise-de-1-emploi. Acesso em: 16 abr. 2020.

COVER, M.; MENEZES, M. A. Estratégias de renda de trabalhadores migrantes e a mecanização da colheita de cana-de-açúcar: um olhar desde o Sertão Paraibano. Estudos Sociedade e Agricultura, v. 28, n. 2, p. 458-475, 2020.

CROCCO, F. L. T. et al. Café, terra e trabalho no município de Nepomuceno-MG. Pegada-A Revista da Geografia do Trabalho, v. 18, n. 3, p. 78-100, set./dez. 2017.

DEATON, B. J.; DEATON, B. J. Food security and Canada's agricultural system challenged by COVID-19. Canadian Journal of Agricultural Economics/Revue Canadienne d'Agroeconomie, v. 68, n. 2, p. 143$149,2020$.

ECLT FOUNDATION. The Impact of COVID-19 on Child Labour in Agriculture. Disponível em: /en/ news/the-impact-of-covid-19-on-child-labour-in-agriculture. Acesso em: 28 abr. 2020.

EURACTIV. COVID-19 measures could cause 'devastating' labour shortage in EU farming, 25 mar. 2020a. Disponível em: https://www.euractiv.com/section/agriculture-food/news/covid-19-measures-could-cause-devastating-labour-shortage-in-eu-farming/. Acesso em: 7 abr. 2020.

EURACTIV. German farms need nearly 300,000 seasonal workers, 25 mar. 2020b. Disponível em: https://www.euractiv.com/section/agriculture-food/news/german-farms-need-nearly-300000-seasonal-workers/. Acesso em: 7 abr. 2020.

FAO. Ending poverty and hunger by investing in agriculture and rural areas. Rome, 2017.

FAO. Impact of COVID-19 on informal workers. Rome, 2020a. 7 p.

FAO. COVID-19 and rural poverty. FAO, 2020b.

FARM BUREAU. Farmers Prioritize Worker Health and Safety. Disponível em: https://www.fb.org/ news/farmers-prioritize-worker-health-and-safety. Acesso em: 28 abr. 2020.

FREITAS, F. G. D.; MAgnabosco, A. L.; BANDEIRA, A. C. A pandemia do Covid-19 e seus impactos na economia mundial e brasileira. Confederação Nacional de Serviços, 2020. 26 p.

G1 RO. Colheita de café é iniciada em RO e Seagri orienta sobre cuidados e prevenção ao coronavírus. Rondônia Rural, 11 abr. 2020. Disponível em: https://g1.globo.com/ro/rondonia/rondonia-rural/noticia/2020/04/11/colheita-de-cafe-e-iniciada-em-ro-e-seagri-orienta-sobre-cuidados-e-prevencao-ao-coronavirus.ghtml. Acesso em: 30 maio 2020.

GLOBO RURAL. Cafeicultor adapta processo de colheita aos tempos de pandemia. Disponível em: https://revistagloborural.globo.com/Noticias/Agricultura/Cafe/noticia/2020/04/cafeicultor-adapta-processo-de-colheita-aos-tempos-de-pandemia.html. Acesso em: 1 maio 2020a.

GLOBO RURAL. Como a Covid-19 mudou o dia-a-dia dos agricultores. 3 maio 2020b. Disponível em: https://g1.globo.com/economia/agronegocios/globo-rural/noticia/2020/05/03/como-a-covid-19-mudou-o-dia-a-dia-dos-agricultores.ghtml. Acesso em: 30 maio 2020. 
GUIMARÃES, E. Cafeicultores estão com medo de faltar mão de obra para a colheita. Revista Attalea Agronegócios, 3 abr. 2020. Disponível em: https://revistadeagronegocios.com.br/cafeicultores-estao-com-medo-de-faltar-mao-de-obra-para-a-colheita-que-comeca-em-breve/. Acesso em: 9 abr. 2020.

IBGE. Censo agropecuário 2017: resultados preliminares. Rio de Janeiro, 2017.

IDELE. [Covid-19] Témoignages d'éleveurs Bovins Lait de l'est. Disponível em: http://idele.fr/no_cache/recherche/publication/idelesolr/recommends/covid-19-temoignages-deleveurs-du-dispositif-inosys-reseaux-delevage-bovin-lait.html. Acesso em: 28 abr. 2020a.

IDELE. [Covid-19] Témoignages d'éleveurs Bovins viande du Limousin. Disponível em: http://idele. fr/no_cache/recherche/publication/idelesolr/recommends/covid-19-temoignages-deleveurs-bovins-viande-du-limousin.html. Acesso em: 28 abr. 2020b.

IDELE. [Covid-19] Des leviers pour réorganiser le travail. Disponível em: http://idele.fr/no_cache/ recherche/publication/idelesolr/recommends/covid-19-des-leviers-pour-reorganiser-son-travail.html. Acesso em: 16 abr. 2020c.

IDELE. [Covid-19] Gestion des salariés pendant la crise. Disponível em: http://idele.fr/no_cache/recherche/publication/idelesolr/recommends/covid-19-gestion-des-salaries-pendant-la-crise.html. Acesso em: 16 abr. $2020 d$.

IDELE. [Covid-19] Préserver la santé des personnes intervenant sur l'élevage. Disponível em: http:// idele.fr/no_cache/recherche/publication/idelesolr/recommends/covid-19-preserver-la-sante-des-personnes-intervenant-sur-lelevage.html. Acesso em: 16 abr. 2020.

IDELE. Covid19 - Protéger sa santé et celle des intervenants en élevage. Les gestes à respecter pour les interventions du vétérinaire. Disponível em: http://idele.fr/fileadmin/medias/Documents/2020_04_02_ Covid19_Fiche_biosecurite_Les_gestes_a_respecter_pour_les_interventions_veto_en_elevage.pdf. Acesso em: 7 abr. 2020.

INTERNATIONAL LABOUR ORGANIZATION. ILO: COVID-19 causes devastating losses in working hours and employment. Press release. Disponível em: http://www.ilo.org/global/about-the-ilo/newsroom/ news/WCMS_740893/lang--en/index.htm. Acesso em: 9 abr. 2020.

IVANOV, D. Predicting the impacts of epidemic outbreaks on global supply chains: a simulation-based analysis on the coronavirus outbreak (COVID-19/SARS-CoV-2) case. Transportation Research Part E: Logistics and Transportation Review, v. 136, p. 101922, 1 abr. 2020.

LARUE, B. Labour issues and COVID-19. Canadian Journal of Agricultural Economics/Revue Canadienne d'Agroeconomie, v. 68, n. 2, p. 231-327, 2020.

MALANSKI, P. D.; SCHIAVI, S.; DEDIEU, B. Characteristics of "work in agriculture" scientific communities. A bibliometric review. Agronomy for Sustainable Development, v. 39, n. 4, p. 36, 19 jun. 2019.

MARTIN, P. et al. How many workers are employed in California agriculture? California Agriculture, v. 71, n. 1, p. 30-34, ago. 2016.

MASUNAGA, S. Why are eggs getting so expensive? Blame coronavirus demand. Los Angeles Times, 8 Abr. 2020. Disponível em: https:/www.latimes.com/business/story/2020-04-08/egg-prices-rising-coronavirus. Acesso em: 16 abr. 2020.

MCEWAN, K. et al. Potential implications of COVID-19 on the Canadian pork industry. Canadian Journal of Agricultural Economics/Revue Canadienne d'Agroeconomie, v. 68, n. 2, p. 201-206, June 2020. 
MCKIBBIN, W. J.; FERNANDO, R. The global macroeconomic impacts of COVID-19: seven scenarios. Rochester, NY: Social Science Research Network, 2020. 45 p. (CAMA Working Paper, 19). Disponível em: https://papers.ssrn.com/abstract=3547729. Acesso em: 7 abr. 2020.

MENDES, E. Colheita do café no Sul de MG começa com boas expectativas, mesmo diante de pandemia. G1 GLOBO. Sul de Minas EPTV, 4 maio 2020. Disponível em: https:/g1.globo.com/mg/sul-de-minas/ noticia/2020/05/04/colheita-do-cafe-no-sul-de-mg-comeca-com-boas-expectativas-mesmo-diante-de-pandemia.ghtml. Acesso em: 30 maio 2020.

MENEZES, M. A. de; SILVA, M. S. da; COVER, M. Migrant workers in sugarcane mills: a study of social networks and recruitment intermediaries in Brazil. Agrarian South: Journal of Political Economy, v. 1, n. 2, p. 161-180, 1 ago. 2012.

MINKOFF-ZERN, L.-A.; SLOAT, S. A new era of civil rights? Latino immigrant farmers and exclusion at the United States Department of Agriculture. Agriculture and Human Values, v. 34, n. 3, p. 631-643, 1 set. 2017.

MINT. Opinion: Farmers may not be infected but are certainly affected. Disponível em: https://www.livemint.com/opinion/online-views/farmers-may-not-be-infected-but-are-certainly-affected-11585597865710.html. Acesso em: 9 abr. 2020.

PORSSE, A. A. et al. Impactos econômicos da COVID-19 no Brasil. Nota Técnica NEDUR-UFPR No 01-2020. Curitiba: Núcleo de Estudos em Desenvolvimento Urbano e Regional, 2020. 22 p.

PREIBISCH, K. Pick-your-own labor: migrant workers and flexibility in Canadian agriculture. International Migration Review, v. 44, n. 2, p. 404-441, 1 jun. 2010.

RICHARDS, T. J.; RICKARD, B. COVID-19 impact on fruit and vegetable markets. Canadian Journal of Agricultural Economics/Revue Canadienne d'Agroeconomie, v. 68, n. 2, p. 189-194, June 2020.

ROGALY, B. Intensification of workplace regimes in British horticulture: the role of migrant workers. Population, Space and Place, v. 14, n. 6, p. 497-510, 1 nov. 2008.

SAFE FOOD QUEENSLAND. Checklist for reducing workforce impact from COVID-19. 5 p. 3 Apr. 2020. Disponível em: https:/www.safefood.qld.gov.au/wp-content/uploads/2020/04/2020-03-04-Checklist-for-Reducing-Workforce-Impact-from-COVID-19-V1.0-.pdf. Acesso em: 7 abr. 2020.

SHAHID, N. et al. Word cloud segmentation for simplified exploration of trending topics on Twitter. IET Software, v. 11, n. 5, p. 214-220, 1 out. 2017.

SOUZA, J. P. de; SCHIAVI, S. M. A. Covid-19 e seus impactos na agricultura e cadeias produtivas. Disponível em: http://www.cpr.uem.br/images/grupo-agro/introducao-covid-agro.pdf. Acesso em: 6 maio. 2020.

TEAGASC. Farm Methodically for Safety. Disponível em: https://www.teagasc.ie/news--events/ news/2020/farm-methodically-for-saf.php. Acesso em: 10 abr. 2020.

TEAGASC. Regional Farm Labour Database being set up. Disponível em: https://www.teagasc.ie/news--events/news/2020/regionalfarmlabourdata.php. Acesso em: 10 abr. 2020.

UN NEWS. COVID-19: impact could cause equivalent of 195 million job losses, says ILO chief. Disponível em: https://news.un.org/en/story/2020/04/1061322. Acesso em: 28 abr. 2020.

USA Today. US agriculture: Can it handle coronavirus, labor shortages and panic buying? Disponível em: https:/www.usatoday.com/story/money/business/2020/04/04/coronavirus-tests-americas-food-supply-agriculture/5096382002/. Acesso em: 1 maio 2020. 
USDA. Coffee: World Markets and Trade. Disponível em: https://apps.fas.usda.gov/psdonline/circulars/ coffee.pdf. Acesso em: 27 jun. 2021.

VILLELA, E. F. de M.; NATAL, D. Mídia, saúde e poder: um jogo de representações sobre dengue. Saúde e Sociedade, v. 23, n. 3, p. 1007-1017, set. 2014.

WOMEN IN INFORMAL EMPLOYMENT: GLOBALIZING AND ORGANIZING. COVID-19, informal workers and WIEGO's work during this crisis. Disponível em: https://www.wiego.org/covid19crisis. Acesso em: 30 maio 2020.

WORLD BANK. Employment in agriculture. Disponível em: https://data.worldbank.org/indicator/ SL.AGR.EMPL.ZS?end=2020\&start=1991\&type=shaded\&view=chart. Acesso em: 21 jan. 2021. 
